\title{
(2) OPEN ACCESS \\ Successful treatment of severe COVID-19 pneumonia and hyperinflammatory syndrome with tocilizumab
}

\author{
Giorgio Gentile (ㅈ, ${ }^{1,2}$ Rebecca Davies, ${ }^{1}$ Valeria Maria Manfreda, ${ }^{1}$ Zain UI Abideen ${ }^{1}$
}

${ }^{1}$ Nephrology, Royal Cornwall Hospitals NHS Trust, Truro, UK 2University of Exeter Medical School, Exeter, UK

\section{Correspondence to}

Dr Giorgio Gentile; giorgio.gentile@nhs.net

Accepted 2 December 2020

\section{SUMMARY}

As of 28 October 2020, there are over 44000000 confirmed COVID-19 infections and over 1000000 deaths worldwide, including 945367 infections and 45765 deaths in the UK. Acute respiratory distress syndrome occurs in $50 \%$ of patients with secondary haemophagocytic lymphohistiocytosis, a hyperinflammatory syndrome characterised by a surge of cytokines, including interleukin 6 (IL-6). Here we describe the case of the first patient with severe COVID-19 pneumonia successfully treated with tocilizumab, a humanised monoclonal antibody against the IL-6 receptor, in the UK. Early treatment (after 7-10 days from the onset of symptoms) with tocilizumab could (1) reduce the risk of requiring non-invasive or invasive ventilation; (2) offer a chance of survival to people who are not fit for escalation or have refused to be ventilated; and (3) potentially increase the chance of survival in some patients who are already ventilated but fail to improve with supportive treatment.

\section{BACKGROUND}

To date, SARS-CoV-2 has caused more than 1000000 deaths worldwide. Death is caused by severe respiratory distress following a surge of interleukins and cytokines. Tocilizumab is a humanised monoclonal antibody against interleukin 6 (IL-6) and has shown promise in preliminary studies in blocking cytokine 'storm' and improving patient outcomes in severe COVID-19 pneumonia. ${ }^{1-3}$

In this case report, we aimed to assess clinical improvement following administration of intravenous tocilizumab in a rapidly deteriorating patient with severe COVID-19 pneumonia.

\section{CASE PRESENTATION}

A man in his early 70s with a medical history of type 2 diabetes and hypertension was admitted to hospital in March 2020 with leg weakness, fever and dry cough. His Rockwood Clinical Frailty Score was $2-3$. Positive findings on clinical examination were hepatomegaly and generalised weakness. Initial observations included peripheral oxygen saturation $\left(\mathrm{SpO}_{2}\right)$ of $97 \%$ on room air and a temperature of $38.4^{\circ} \mathrm{C}$. Chest X-ray on admission was unremarkable. Nasopharyngeal swab confirmed the presence of SARS-CoV-2 RNA, in keeping with COVID-19 infection.

Over the following week, our patient had continuing fever and required an increasing flow of supplemental oxygen to maintain adequate $\mathrm{SpO}_{2}$. He was started on empirical antibiotics in case of coexistent bacterial infection. A treatment escalation plan had been discussed with the patient and he had declined admission to intensive care for ventilatory support. The patient was increasingly dyspnoeic and hypoxic with $\mathrm{SpO}_{2} \sim 80 \%$ on $19 \mathrm{~L} /$ min oxygen and rapidly deteriorating with respiratory distress. Repeat chest X-ray demonstrated new bilateral air space opacification, in keeping with severe pneumonitis (figure 1).

\section{TREATMENT}

An emergency application for tocilizumab treatment was approved on compassionate grounds, and $8 \mathrm{mg} / \mathrm{kg}$ intravenous tocilizumab was administered in two doses 12 hours apart. No absolute contraindications (neutrophils $<1 \times 10^{9} / \mathrm{L}$, platelets $<100 \times 10^{9} / \mathrm{L}$, aspartate aminotransferase (AST) $>3 \times$ upper limit of normal, or severe active bacterial or opportunistic infection) were present. Hepatitis $\mathrm{B}$ and $\mathrm{C}$ and tuberculosis screening were not performed in light of the life-threatening clinical picture. The patient did not receive any concomitant treatment with dexamethasone, remdesivir or hydroxychloroquine.

\section{OUTCOME AND FOLLOW-UP}

Over the following 24 days, $\mathrm{SpO}_{2}$ drastically improved and the delivered oxygen dose decreased (figure 2). The patient did not develop any complications from tocilizumab therapy and was discharged home on day 35 after admission once he was able to maintain $\mathrm{SpO}_{2}>92 \%$ without supplemental oxygen.

\section{DISCUSSION}

Tocilizumab is a humanised monoclonal antibody against the IL- 6 receptor. It is licensed for use in patients with rheumatoid arthritis. ${ }^{4}$

In patients with severe COVID-19, there is secondary haemophagocytic lymphohistiocytosis (sHLH). This is characterised by cytokine storm (a surge of IL-2, IL-6, IL-7, tumour necrosis factor $\alpha$, granulocyte-colony stimulating factor) and multiorgan failure. ${ }^{3}$ A tool to aid diagnosis is the 'Hscore'. This score takes into account any underlying immunosuppressing disorders, temperature, presence of hepatomegaly/splenomegaly, AST, ferritin, triglyceride, any cytopaenia and haemophagocytosis on bone marrow aspirate. Our patient had a score of at least 169 at the time of the infusion, translating to a strong possibility of sHLH. ${ }^{5}$ This is relevant as $50 \%$ of patients with sHLH develop acute respiratory distress syndrome (ARDS).

The Berlin definition for severe ARDS is an acute deterioration (1 week or less) with bilateral chest 


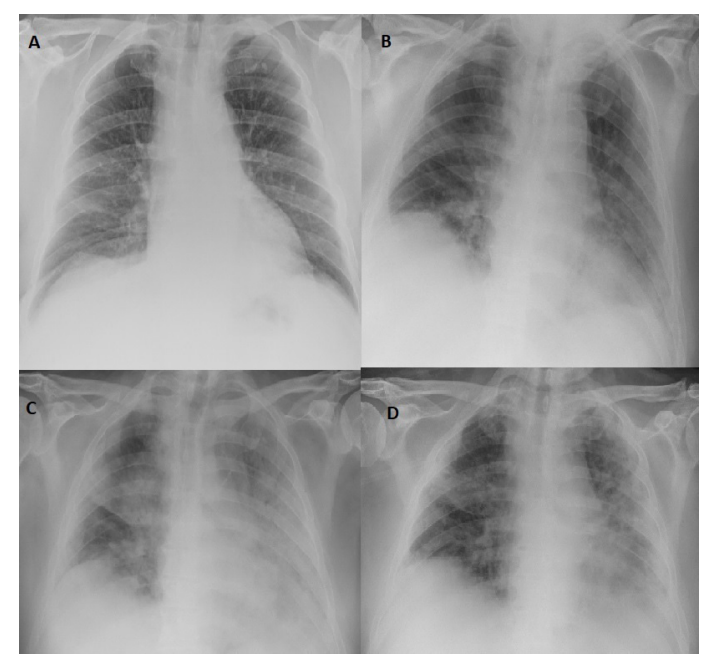

Figure 1 Serial chest X-rays during hospital stay: (A) on admission; (B) 7 days from admission, before tocilizumab; (C) 1 week post tocilizumab; and (D) 2 weeks post tocilizumab.

X-ray changes and partial pressure of oxygen $\left(\mathrm{PaO}_{2}\right)$ :fraction of inspired oxygen $\left(\mathrm{FiO}_{2}\right)$ ratio $<100 \mathrm{~mm} \mathrm{Hg}$ with positive end expiratory pressure (PEEP) $>5 \mathrm{~mm} \mathrm{Hg}$. Severe ARDS is associated with a mortality of $45 \%$ even in the absence of COVID-19. Since we were managing our patient within the confines of a ward and not intensive care unit (ICU), we were unable to supply PEEP and so our patient does not meet the criteria for ARDS, but he certainly had severe COVID-19-related acute respiratory distress. This greatly improved post-tocilizumab infusion with rapid reduction in inspired oxygen and increase in $\mathrm{SpO}_{2}$, and we propose that this is due to IL-6 blockade from tocilizumab.

To the best of our knowledge, we have described the first successful treatment of severe COVID-19 pneumonia and concomitant hyperinflammatory syndrome with tocilizumab in the UK. Tocilizumab is potentially crucial in blocking the cytokine storm and associated ARDS which might develop in a subset of patients with COVID-19. Based on the described case, we speculate that tocilizumab and other anti-IL-6 drugs including sarilumab ${ }^{6}$ should be administered as soon as possible in patients who develop an abrupt clinical deterioration 7-10 days from the initial onset of symptoms and have a high Hscore (169 or above), corresponding to a sensitivity of $93 \%$, specificity of $86 \%$ and accurate classification of $90 \%$ of patients with hyperinflammatory syndrome. ${ }^{5}$ Early tocilizumab treatment could

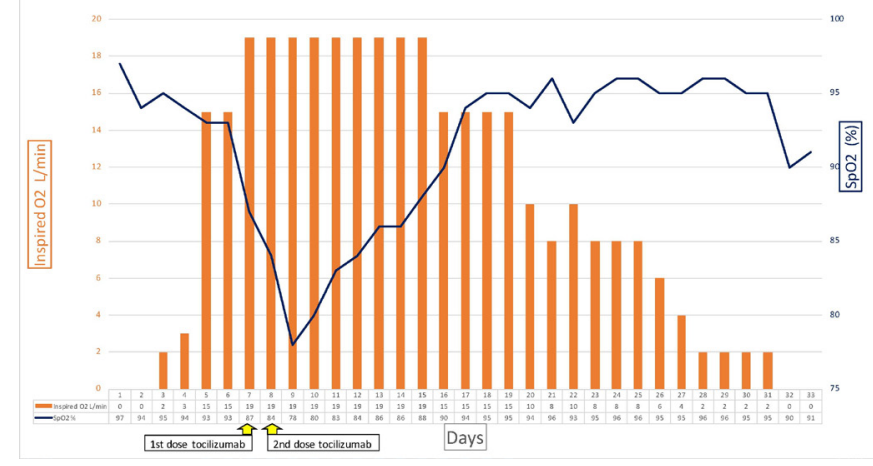

Figure 2 Inspired oxygen in L/min (left y-axis) and peripheral oxygen saturation $\left(\mathrm{SpO}_{2}\right)$ in \% (right y-axis) over time. potentially (1) reduce the risk of requiring non-invasive or invasive ventilation; (2) offer a chance of survival to people who are unfit for escalation or have refused to be ventilated; and (3) potentially increase the chance of survival in some patients who are already ventilated but fail to improve with supportive treatment. However, in ICU patients the established degree of inflammatory lung damage might be too extensive to be reversible and additional complications might be present, including deranged coagulation function, disseminated intravascular coagulation and pulmonary embolism. Also, tocilizumab treatment should be avoided in people with severe active infections, including tuberculosis and hepatitis B. Finally, severe and sometimes fatal infections have been reported after tocilizumab treatment, although tocilizumab did not significantly increase the risk of infection in severely immunocompromised patients with haematological malignancy. ${ }^{7}$

The present case report is relevant for two main reasons. First, a unique peculiarity of this case is that the patient received tocilizumab treatment in the predexamethasone era, as no data on dexamethasone had been made available from the RECOVERY (Randomized Evaluation of COVID-19 Therapy) researchers at the time, or indeed on any other medications, including remdesivir. Hence, the very favourable effects of tocilizumab in this patient have not been potentially enhanced, or indeed completely explained, by other concomitant treatments, including dexamethasone or remdesivir.

Second, and most importantly, this case report shows a clear-cut temporal association between tocilizumab administration and rapid improvement in the clinical condition in a patient with clear hyperinflammatory syndrome, as highlighted by an Hscore of 169. This is a crucial point, as two randomised controlled trials aimed at evaluating the role of tocilizumab in severe COVID-19 pneumonia, the RECOVERY ${ }^{8}$ and the COVACTA (Study to Evaluate the Safety and Efficacy of Tocilizumab in Patients With Severe COVID-19 Pneumonia) ${ }^{9}$ trials, did not include the Hscore among the inclusion criteria. Indeed, under the overwhelming pressure of the urgent need for effective treatments against the COVID-19 pandemic, both studies decided to adopt much broader and somewhat aspecific inclusion criteria (for instance, $\mathrm{C}$ reactive protein $\geq 75 \mathrm{mg} / \mathrm{L}$ and oxygen saturation $<92 \%$ on room air or requiring oxygen in the RECOVERY trial). As pointed out by Furlow, ${ }^{10}$ this issue might explain the disappointing preliminary results of the COVACTA trial, still unpublished but announced by Hoffmann-La Roche on 29 July 2020, which show that tocilizumab failed to meet its primary endpoint of improved clinical status and to improve mortality, although patients receiving tocilizumab had shorter hospitalisation time compared with the placebo arm. Tocilizumab continues to be evaluated by the RECOVERY trial, which enrolled over 850 patients, almost twice the size of the COVACTA trial, and might confirm or refute the results of COVACTA. Independently from the results of the RECOVERY trial, which suffers from the same limitations as COVACTA (lack of stratification by clinical signs of hyperinflammatory syndrome), we genuinely hope that the current case report could encourage researchers to perform post-hoc analyses of the above studies in due course or, even better, to design new randomised controlled trials which include Hscore as one of the key inclusion criteria.

Acknowledgements The Authors would like to thank Kate Shields (Chief Executive), Allister Grant (Medical Director), Gillian Derrick (Deputy Medical Director), Andrew Pothecary (Specialist Pharmacist) and lain Davidson (Chief Pharmacist) at the Royal Cornwall Hospitals NHS Trust for their invaluable support in the decisionmaking process, and drug procurement out-of-hours. The Authors would also like 
Learning points

- This is the first description of the successful usage of tocilizumab in severe COVID-19 pneumonia in the UK.

- This is timely and informative for front-line clinicians worldwide, as multiple trials have just started to explore the role of tocilizumab in COVID-19 pneumonia, including the RECOVERY (Randomized Evaluation of COVID-19 Therapy) trial in the UK and the COVACTA (Study to Evaluate the Safety and Efficacy of Tocilizumab in Patients With Severe COVID-19 Pneumonia) trial in the USA.

- Our case report might be helpful in encouraging researchers to consider treatment with tocilizumab in patients with COVID-19 who are not suitable for non-invasive or invasive ventilation, have refused to be ventilated, or are already ventilated in intensive care.

- The findings of our case report need to be confirmed by well-designed randomised controlled trials in patients with COVID-19, which should ideally include a high Hscore (169 or above) among the inclusion criteria.

to pay homage to David George, Kathleen Gulaga, Leonardo Giunta, Sarah Bland, Natalie Cookman, Zoe Dodgeson, Joanna Anderton, Lisa Wayne, and the whole nursing staff on Wheal Prosper isolation ward for their selfless and compassionate care and their absolute dedication to patients.

Contributors GG conceived the study. GG, RD, VMM and ZUA collected, analysed and interpreted the clinical data. GG and VMM searched the literature. GG and ZUA prepared the figures. GG and ZUA wrote the manuscript. RD and VMM critically revised the manuscript. All authors agreed to be accountable for all aspects of the work in ensuring that questions related to the accuracy or integrity of any part of the work are appropriately investigated and resolved. All authors gave final approval of the manuscript.

Funding The authors have not declared a specific grant for this research from any funding agency in the public, commercial or not-for-profit sectors.
Competing interests None declared.

Patient consent for publication Obtained.

Provenance and peer review Not commissioned; externally peer reviewed.

Open access This is an open access article distributed in accordance with the Creative Commons Attribution Non Commercial (CC BY-NC 4.0) license, which permits others to distribute, remix, adapt, build upon this work non-commercially, and license their derivative works on different terms, provided the original work is properly cited and the use is non-commercial. See: http://creativecommons.org/ licenses/by-nc/4.0/.

\section{ORCID iD}

Giorgio Gentile http://orcid.org/0000-0003-1260-8307

\section{REFERENCES}

1 Xu X-W, Wu X-X, Jiang X-G, et al. Clinical findings in a group of patients infected with the 2019 novel coronavirus (SARS-Cov-2) outside of Wuhan, China: retrospective case series. BMJ 2020;368:m606.

2 Rossotti R, Travi G, Ughi N, et al. Safety and efficacy of anti-il6-receptor tocilizumab use in severe and critical patients affected by coronavirus disease 2019: a comparative analysis. J Infect 2020;81:e11-17.

3 Sinha P, Mostaghim A, Bielick CG, et al. Early administration of interleukin-6 inhibitors for patients with severe COVID-19 disease is associated with decreased intubation, reduced mortality, and increased discharge. Int J Infect Dis 2020;99:28-33.

4 Oldfield V, Dhillon S, Plosker GL. Tocilizumab: a review of its use in the management of rheumatoid arthritis. Drugs 2009;69:609-32.

5 Mehta P, McAuley DF, Brown M, et al. COVID-19: consider cytokine storm syndromes and immunosuppression. Lancet 2020;395:1033-4.

6 Evaluation of the efficacy and safety of Sarilumab in hospitalized patients with COVID-19. Available: https://clinicaltrialsgov/ct2/show/study/NCT04315298 [Accessed 22 Apr 2020].

7 Frigault MJ, Nikiforow S, Mansour MK, et al. Tocilizumab not associated with increased infection risk after CAR T-cell therapy: implications for COVID-19? Blood 2020;136:137-9.

8 The RECOVERY trial Study Group. Available: https://www.recoverytrial.net/ [Accessed 22 Apr 2020].

9 The COVACTA trial study group. Study to evaluate the safety and efficacy of tocilizumab in patients with severe COVID-19 pneumonia (COVACTA). Available: https://clinicaltrialsgov/ct2/show/NCT04320615 [Accessed 22 Apr 2020].

10 Furlow B. COVACTA trial raises questions about tocilizumab's benefit in COVID-19. Lancet Rheumatol 2020:2:e592.

Copyright 2021 BMJ Publishing Group. All rights reserved. For permission to reuse any of this content visit

https://www.bmj.com/company/products-services/rights-and-licensing/permissions/

BMJ Case Report Fellows may re-use this article for personal use and teaching without any further permission.

Become a Fellow of BMJ Case Reports today and you can:

- Submit as many cases as you like

- Enjoy fast sympathetic peer review and rapid publication of accepted articles

- Access all the published articles

Re-use any of the published material for personal use and teaching without further permission

Customer Service

If you have any further queries about your subscription, please contact our customer services team on +44 (0) 2071111105 or via email at support@bmj.com.

Visit casereports.bmj.com for more articles like this and to become a Fellow 